\title{
Endoscopic resection of ectopic pancreas in the minor papilla
}

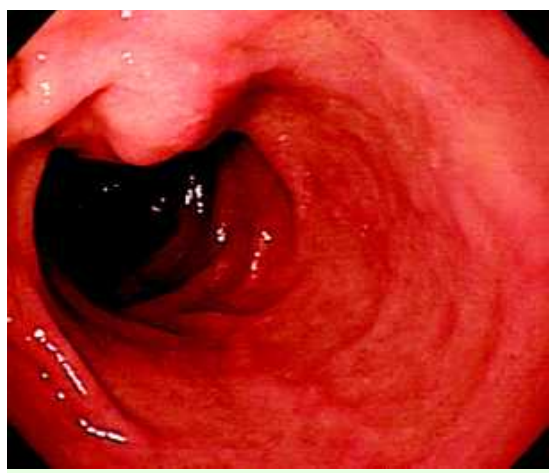

Fig. 1 A hard mass with normal-appearing overlying mucosa was found in the minor papilla area.

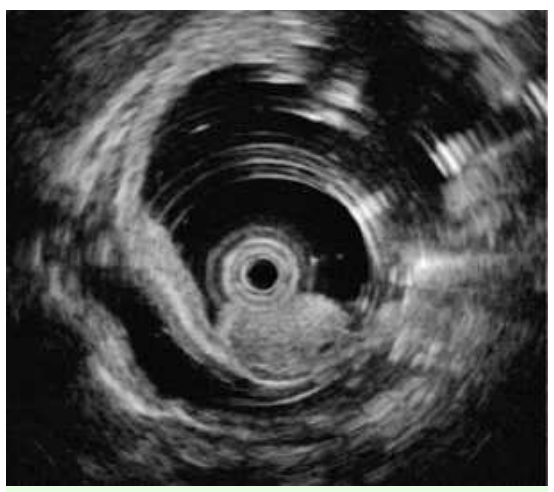

Fig. 2 Endoscopic ultrasound image of lesion.

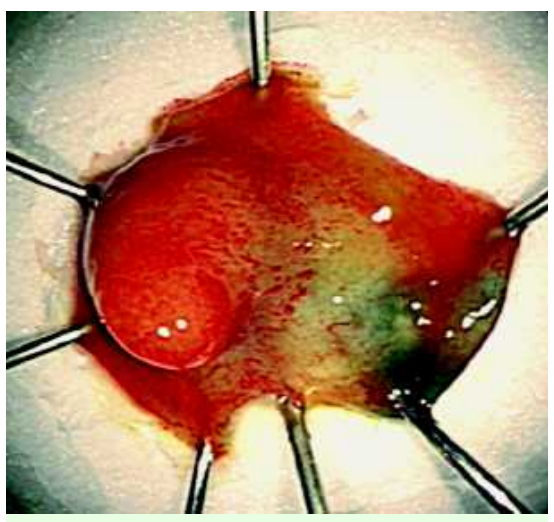

Fig. 3 The lesion was removed by endoscopic mucosal resection.

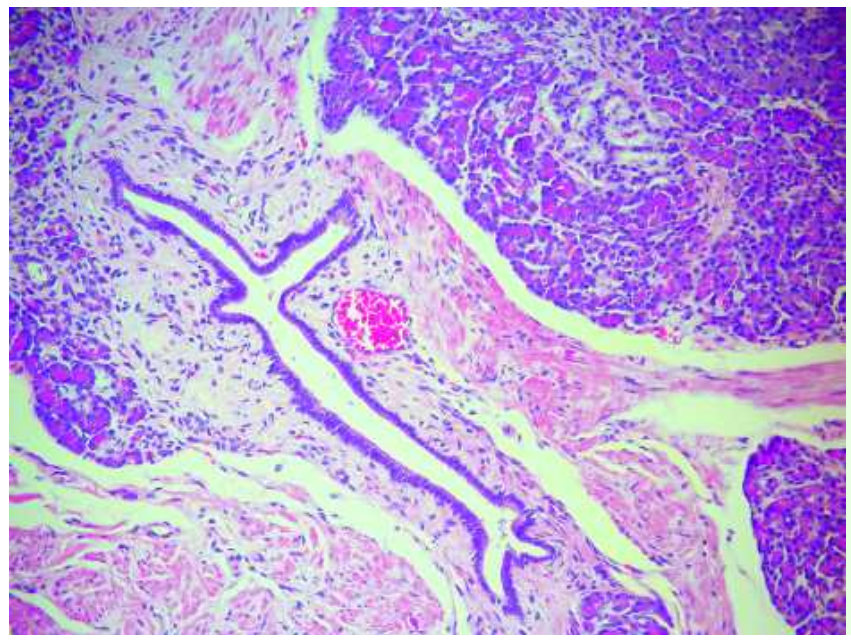

Fig. 4 The lesion was composed of pancreatic acini, ducts, and foci of Langerhans islets, consistent with ectopic pancreas (hematoxylin and eosin stain, $\times 200$ ).

A 50-year-old Korean man underwent upper endoscopy in our hospital for the evaluation of dyspepsia. He had no significant medical history and was taking no medication.

He was found to have a hard mass with normal-appearing overlying mucosa on the minor papilla area just proximal to the normal major papilla ( $\bullet$ Fig. 1 ). Back-to-back duodenoscopy showed the lesion as more prominent. Endoscopic ultrasonography (EUS) was carried out to further evaluate the lesion. Using a 12$\mathrm{MHz}$ transducer, a five-layered gastric wall structure was imaged. EUS revealed a round hypoechoic inhomogeneous lesion, with a few anechoic structures inside, originating from the submucosal layer ( $\bullet$ Fig. 2). The lesion was measured as $9.5 \times 5.0 \mathrm{~mm}$ in size.

The lesion was successfully removed with a snare by endoscopic mucosal resection (๑ Fig.3). Microscopic examination revealed the mass to be composed of pancreatic acini, ducts, and foci of Langerhans islets, consistent with ectopic pancreas ( $\bullet$ Fig. 4). This is a rare case of submucosal tumor of the minor papilla.

Endoscopy_UCTN_Code_TTT_1AR_2AK

\section{K. J. Kim}

Division of Gastroenterology, Department of Internal Medicine, Kosin University College of Medicine, Busan, Korea

\section{Bibliography}

DOI $10.1055 / \mathrm{s}-0028-1103467$

Endoscopy 2009; 41: E12

(c) Georg Thieme Verlag KG Stuttgart · New York . ISSN 0013-726X

\section{Corresponding author \\ K. J. Kim, MD}

Division of Gastroenterology

Department of Internal Medicine

Kosin University College of Medicine

34 Amnam-dong

Seo-gu

Busan 602-702

Korea

Fax: +82-51-9905206

drkkj@paran.com 